\title{
Bundle Size Engineering of Single-Walled Carbon Nanotubes on Silica Nanoparticles
}

\author{
Deok Min Seo, ${ }^{1}$ Myung Gwan Hahm, ${ }^{1}$ and Young Lae Kim² \\ ${ }^{1}$ Department of Materials Science and Engineering, Inha University, 100 Inha-ro, Nam-gu, Incheon 22212, Republic of Korea \\ ${ }^{2}$ Department of Mechanical and Industrial Engineering, Northeastern University, 360 Huntington Avenue, Boston, MA 02115, USA \\ Correspondence should be addressed to Young Lae Kim; ylkim96@gmail.com
}

Received 16 March 2017; Accepted 7 May 2017; Published 30 May 2017

Academic Editor: Andrew R. Barron

Copyright (c) 2017 Deok Min Seo et al. This is an open access article distributed under the Creative Commons Attribution License, which permits unrestricted use, distribution, and reproduction in any medium, provided the original work is properly cited.

\begin{abstract}
Small and large single-walled carbon nanotubes (SWCNTs) bundles from different-sized cobalt catalyst clusters have been synthesized and prepared through chemical vapor deposition (CVD) method by using Co-acetate ethanol solution with silica nanoparticles. By controlling concentration of Co-acetate ethanol solution ( $0.2 \mathrm{wt} \%$ and $0.4 \mathrm{wt} \%)$, various sizes and types of bundle of SWCNTs are grown on the silica nanoparticle substrates. Synthesized SWCNT's diameter ranged from $0.92 \mathrm{~nm}$ to $1.63 \mathrm{~nm}$, and chirality of SWCNTs and their electronic property from high concentration solution show diverse characteristics. In high concentration solution, the large number of cobalt clusters is induced to merge on the surface of silica nanoparticles and then lots of nucleation points are provided by cobalt clusters for growth of SWNTs. These results give us a promising path to selectively synthesize various types of SWCNTs with different shapes of merged cobalt catalyst. Engineering bundle sizes of SWCNTs can be promising key for diverse applications of carbon nanotubes.
\end{abstract}

\section{Introduction}

In the last few decades, carbon nanotubes (CNTs) have been attracting attention due to their unique and outstanding structural, electrical, and mechanical properties [1]. High temperature preparation techniques such as arc discharge or laser ablation opened the pathway to produce CNTs. Later, chemical vapor deposition (CVD) process developed synthesizing technique of CNTs with highly controlled morphology and other properties [2]. It is well-known that size of the catalytic nanoparticle is closely correlated with the tube diameters. To control CNTs diameter, size distribution of catalytic nanoparticles, growth temperature, pressure, reaction time, and amount of carbon source should be controlled [3]. Recently, flurry of research activities was conducted to investigate correlations between characteristics of CNTs and its synthesis methods [4-6] for chirality-selective growth of CNTs [7]. However, there are still too many hurdles to realize bundle size control of single-walled carbon nanotubes (SWCNTs). The correlations between bundle size and properties of CNTs have been rarely discussed because of the complicated correlation between mechanism of CNTs bundling and synthesis methods. These challenges can be fulfilled by synthesizing methods focused on relations between morphology of catalyst particles and bundle size of nanotubes. In this paper, we demonstrated size-selective growth of SWCNTs bundle by alternating the morphology of cobalt clusters formed on the surface of silica nanoparticles, by facile catalyst preparation and chemical vapor deposition (CVD) process. We also investigated the correlation between bundle size and properties of SWCNTs. The results are expected to be useful for various applications of SWNTs due to their selectivity on the size and electrical properties of synthesized nanotubes.

\section{Experimental Details}

2.1. Preparation of Catalyst System. The goal of this experiment is to control selectively the growth size of SWCNT bundles by controlling the size of cobalt nanoparticle clusters. Figure 1 shows a schematic drawing of synthesis process. Different concentrations of ethanol-based cobalt-acetate solutions were utilized to synthesize small and large bundles of SWCNTs selectively. $0.2 \mathrm{wt} \%$ and $0.4 \mathrm{wt} \%$ of cobalt-acetate $\left((\mathrm{CH} 3 \mathrm{COOH})_{2} \mathrm{CO} \cdot \mathrm{H}_{2} \mathrm{O}\right)$ powders were dissolved in high 


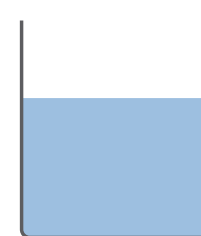

(a)

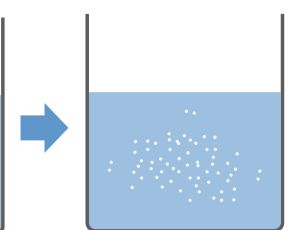

(b)

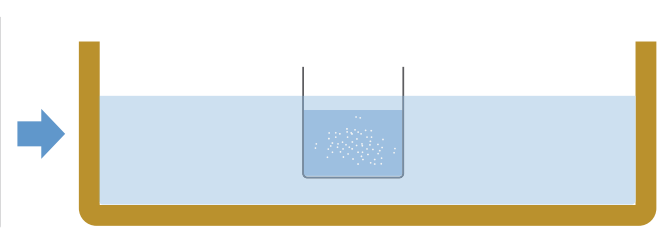

(c)

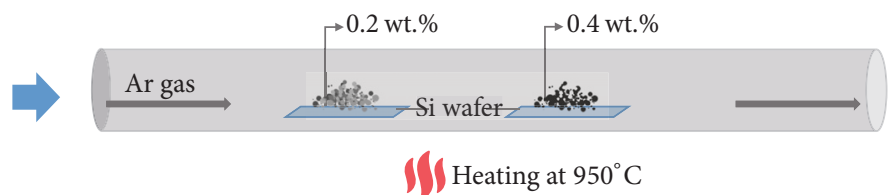

(d)

FIGURE 1: Schematics of single-walled carbon nanotubes synthesis by chemical vapor deposition process. (a) At first, cobalt-acetate ethanol solution ( $0.2 \mathrm{wt} \%$ and $0.4 \mathrm{wt} \%$ ) is prepared. (b) $50 \mathrm{~nm}$ and $200 \mathrm{~nm}$ silica nanoparticles were added to Co-acetate ethanol solution. (c) Ultrasonication of the solution for 90 minutes in bath-type sonicator. Cobalt particles gather together making clusters on the surface of silica nanoparticles. (d) Previous sample is dropped on Si wafer and dried. This wafer goes through the CVD process.

purity ethanol (99.95\%). And then, small amounts of $50 \mathrm{~nm}$ and $200 \mathrm{~nm}$ diameter silica nanoparticles were added to ethanol-based cobalt-acetate solutions $(0.2 \mathrm{wt} \%$ and $0.4 \mathrm{wt} \%)$. These silica nanoparticles are substrates for the growth of SWCNTs. The solution was ultrasonicated for 90 minutes in bath-type sonicator. During sonication, silica nanoparticles were dispersed and clusters of Co particles were formed on the surface of silica nanoparticles as a catalyst for SWCNTs growth.

\subsection{Synthesis of Single-Walled Carbon Nanotubes on Silica} Nanoparticles. Synthesis of SWCNTs was carried out by using a thermal CVD process. Sonicated solution was dropped on $\mathrm{Si}$ wafer $(1 \mathrm{~cm} \times 1 \mathrm{~cm})$ by pipette. The wafer was then dried and baked in furnace at $400^{\circ} \mathrm{C}$ for 5 minutes in air to burn-out organic materials. Prepared substrate was placed in a quartz tube inside a furnace. After that, the quartz tube was evacuated, and high purity argon gas (99.9\%) as a carrier gas was flowed into the quartz tube and simultaneously temperature was heated up to $950^{\circ} \mathrm{C}$. After the desired temperature was reached, Ar gas was stopped and high purity methane $(99.99 \%, 100 \mathrm{sccm}, 5 \mathrm{~min})$ was introduced as a carbon source for SWCNTs growth. After the reaction, methane gas was stopped and Ar gas was supplied again during the temperature cooling to room temperature.

\section{Results and Discussion}

Figure 2 shows the scanning electron microscopy (SEM) images of small-bundled SWCNTs grown on silica nanoparticles with 0.2 wt $\%$ Co-acetate ethanol solution. Small-bundled SWCNTs networks on nanosized silica particles are shown in Figures 2(a) and 2(c). Shown in the figures, catalyst formed with ethanol-based Co-acetate solution on silica nanoparticles is very effective for the synthesis of SWCNTs. Co nanoparticles are formed clusters on the surface of silica nanoparticles as shown in Figures 2(b) and 2(d) (small, white dots on the surface of silica particles). Figure 2(b) shows that small bundles of SWCNTs with $8 \mathrm{~nm}$ mean bundle diameter are grown from Co nanoclusters on the surface of $50 \mathrm{~nm}$ silica particles. In Figure 2(d), mean bundle size of SWCNTs bundles on the $200 \mathrm{~nm}$ silica particles is around $12 \mathrm{~nm}$. Figure 3 shows the SEM images of networks composed of bundled SWNTs grown with $0.4 \mathrm{wt} \% \mathrm{Co}$-acetate ethanol solution. CVD parameters for synthesis large-bundled SWNTs were fixed with $0.2 \mathrm{wt} \%$ solution samples. Figures $3(\mathrm{a})$ and 3(b) show SWCNTs grown on $50 \mathrm{~nm}$ silica nanoparticles and Figures 3(c) and 3(d) show SWCNTs synthesized with $200 \mathrm{~nm}$ silica nanoparticles. Clustered Co particles are also shown in Figures 3(c) and 3(d). By using high concentration Co-acetate ethanol solution $(0.4 \mathrm{wt} \%)$, relatively larger numbers of Co catalyst particles are assembled closely in one cluster compared to the use of low concentration solution $(0.2 \mathrm{wt} \%)$. Since many Co catalyst particles gathered together, a greater number of SWNTs can be grown from one cluster of Co catalyst and the distance between clusters is much closer than one of low concentration solution. Moreover, the bundles of SWCNTs are also connected with small diameter SWCNTs nearby via van der Waals force, resulting in larger bundle sizes of SWCNTs. The diameter of large bundles in Figure 3(b) is about $14 \mathrm{~nm}$ ( $50 \mathrm{~nm}$ silica particles). And for $200 \mathrm{~nm}$ silica particles (Figure 3(d)), mean bundle size is about $32 \mathrm{~nm}$.

To investigate diameter distributions of as-grown SWCNTs, radial breathing mode (RBM) Raman spectra were recorded from SWCNTs synthesized with two different concentrated Co-acetate solutions on the surface of $200 \mathrm{~nm}$ silica particle. Figure 4(a) shows two RBM Raman spectra of small (red curve) and large (blue curve) bundled SWCNTs. Peaks near $300 \mathrm{~cm}^{-1}$ exhibit the peak of Si wafer. And RMB peaks of SWCNTs are in the range of around $100 \sim 300 \mathrm{~cm}^{-1}$, shown in Figure 4(a). Diameter of SWCNTs can be calculated by RBM [8-13]. The RBM frequency is proportional to the inverse diameter of the nanotube: $\omega^{\mathrm{RMB}}=C / d$, where $\omega^{\mathrm{RMB}}$ is Raman shift of radial breathing mode and $d$ is diameter of SWCNTs of corresponding RBM peak and $C$ is constant 


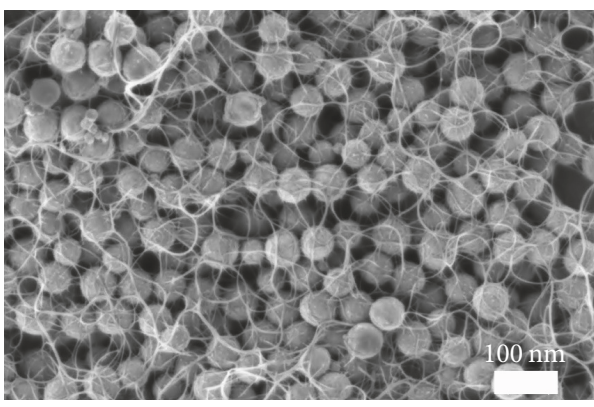

(a)

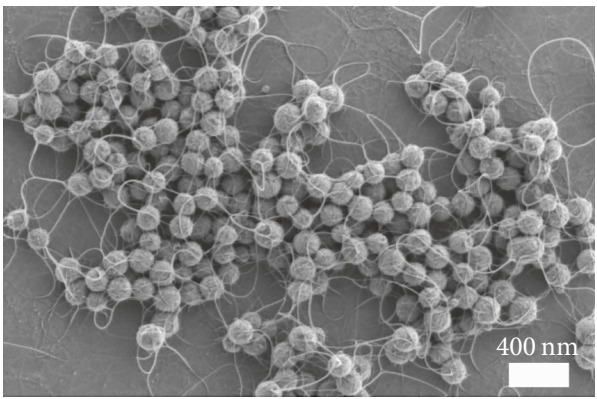

(c)

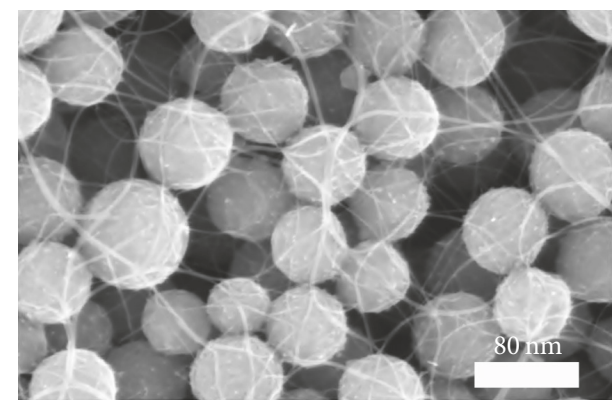

(b)

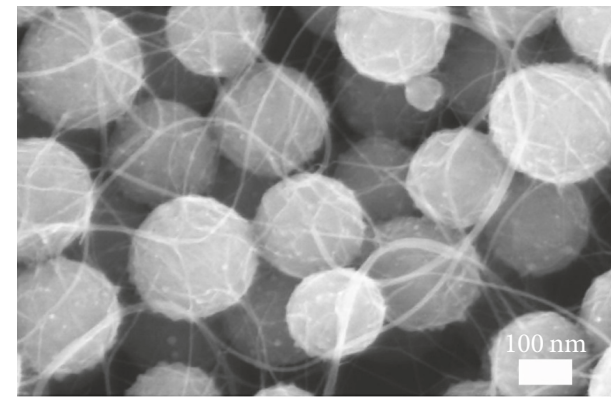

(d)

FIGURE 2: Scanning electron microscopy images of small bundles of SWNTs. Low and high magnification SEM images of small-bundled SWNTs networks grown from $0.2 \mathrm{wt} \%$ Co-acetate ethanol solution. (a) Two- or three-dimensional SWNTs bundles networks are grown on $50 \mathrm{~nm}$ silica nanoparticles. (b) High magnification SEM image of the same sample shown at (a). Small size bundles of SWNTs are interconnected on silica nanoparticles. (c) SWNTs bundles grown on $200 \mathrm{~nm}$ silica nanoparticles. (d) High magnification SEM image of sample on $200 \mathrm{~nm}$ silica nanoparticles. The bundle size is slightly bigger than that of image (b).

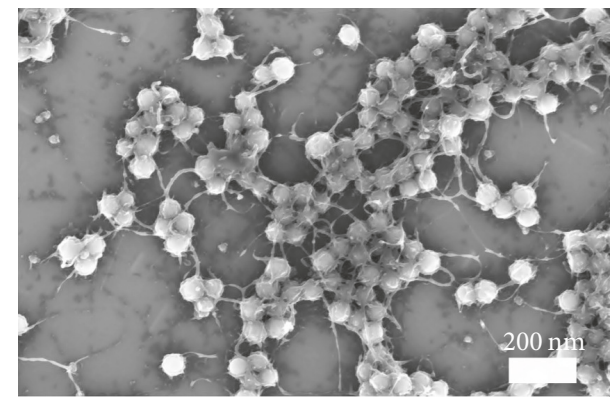

(a)

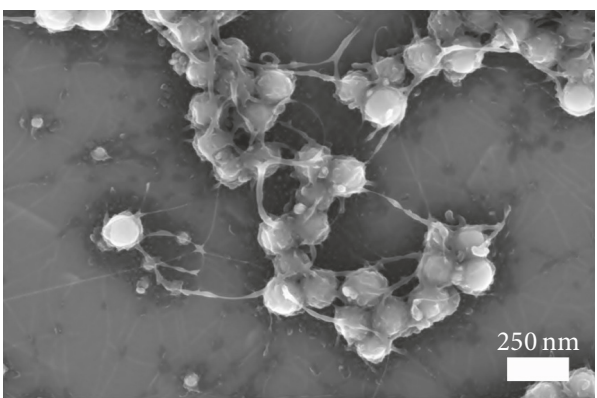

(c)

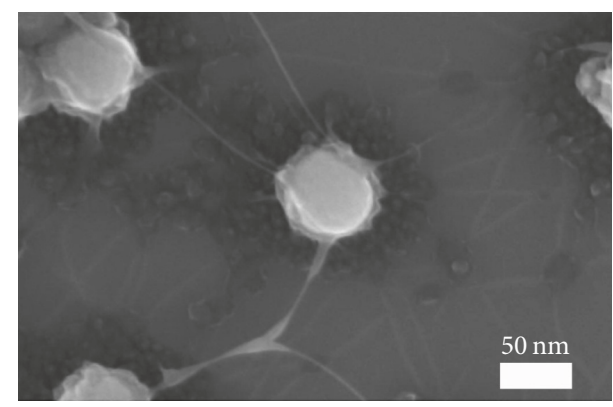

(b)

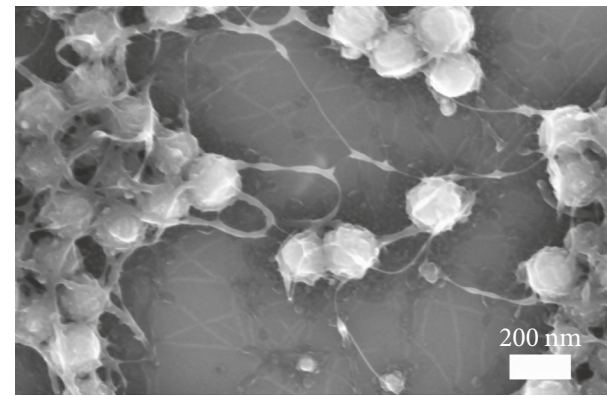

(d)

FIGURE 3: Scanning electron microscopy images of large bundles of SWNTs. Low and high magnification SEM images of small-bundled SWNTs networks grown from $0.4 \mathrm{wt} \%$ Co-acetate ethanol solution. (a) Network of bundled SWNTs on 50 nm silica nanoparticles. (b) High magnification image of (a). SWNTs bundles are grown from silica nanoparticles and make connection with each other. (c) SEM image of SWNT bundles on $200 \mathrm{~nm}$ silica nanoparticles. (d) High magnification image of (c). More and bigger bundles are grown from silica particles and also make more connections with other bundles or SWNTs. 


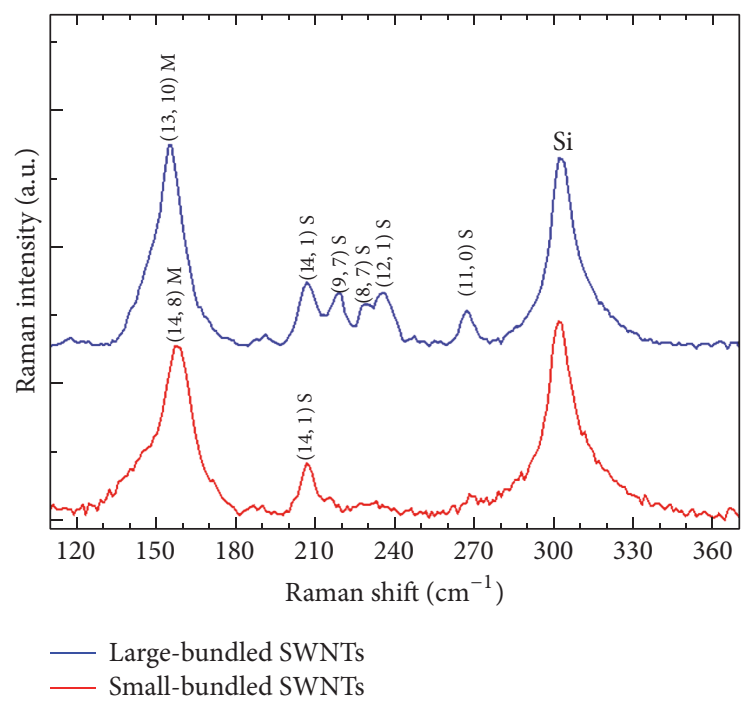

(a)

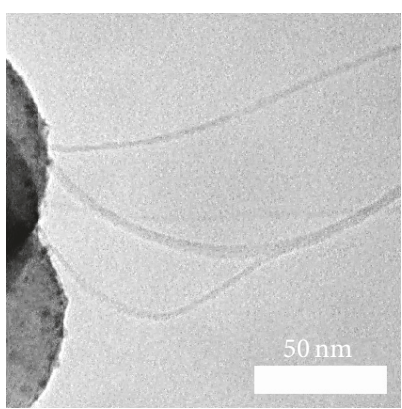

(b)

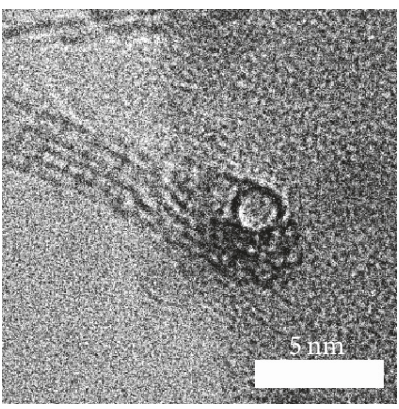

(d)

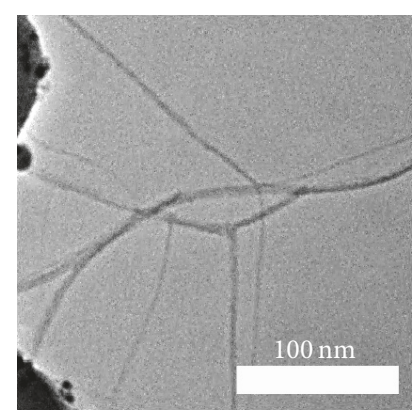

(c)

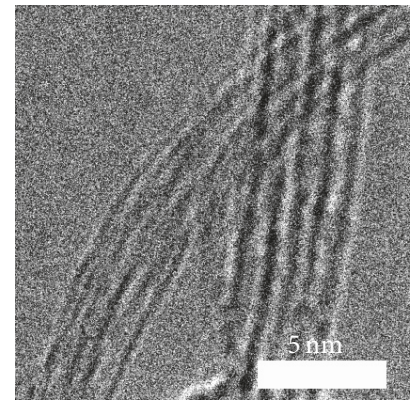

(e)

FIGURE 4: Raman spectra and transmission electron microscopy images from small- and large-bundled SWNTs grown from cobalt clusters on $200 \mathrm{~nm}$ silica particle. (a) Raman spectra of large-bundled SWNTs are colored in blue. This curve shows 6 representative peaks $\left(152 \mathrm{~cm}^{-1}\right.$, $208 \mathrm{~cm}^{-1}, 219 \mathrm{~cm}^{-1}, 228 \mathrm{~cm}^{-1}, 236 \mathrm{~cm}^{-1}$, and $268 \mathrm{~cm}^{-1}$ ). Small-bundled SWNTs (red colored spectra) show 2 representative peaks $\left(158 \mathrm{~cm}^{-1}\right.$ and $207 \mathrm{~cm}^{-1}$ ). Each peak has information about corresponding nanotubes chirality and electronic property. ( $\left.n, m\right)$ shows chiral vector of tube. $\mathrm{M}$ means the tube is metallic and S means semiconducting. Raman spectra of large-bundled SWNTs (blue) show more various and higher peaks. (b, c) TEM images of $0.2 \mathrm{wt} \%$ (c) and $0.4 \mathrm{wt} \%$ (d) samples. Several bundles are grown from Co clusters on the surface of silica particles making connection with each other. (d, e) High magnification TEM images show a bundle of SWNTs. Solutions concentration is $0.2 \mathrm{wt} \%$ for (d) and $0.4 \mathrm{wt} \%$ for (e). Several SWNTs construct one bundle and they are aligned with the direction of bundle. Bigger bundle is grown from higher concentration $(0.4 \mathrm{wt} \%)$ sample.

meaning that RBM Raman shift and diameter of nanotubes are in inversely proportional relation $[8-12,14]$. We used $247 \mathrm{~cm}^{-1} \cdot \mathrm{nm}$ for the value of constant $C$. The representative peaks of RBM from large-bundled SWCNTs are $152 \mathrm{~cm}^{-1}$,
$208 \mathrm{~cm}^{-1}, 219 \mathrm{~cm}^{-1}, 228 \mathrm{~cm}^{-1}, 236 \mathrm{~cm}^{-1}$, and $268 \mathrm{~cm}^{-1}$. Nanotube diameters corresponding to each six RBM frequencies are $1.63 \mathrm{~nm}\left(152 \mathrm{~cm}^{-1}\right), 1.19 \mathrm{~nm}\left(208 \mathrm{~cm}^{-1}\right), 1.13 \mathrm{~nm}$ $\left(219 \mathrm{~cm}^{-1}\right), 1.08 \mathrm{~nm}\left(228 \mathrm{~cm}^{-1}\right), 1.05 \mathrm{~nm}\left(236 \mathrm{~cm}^{-1}\right)$, and 


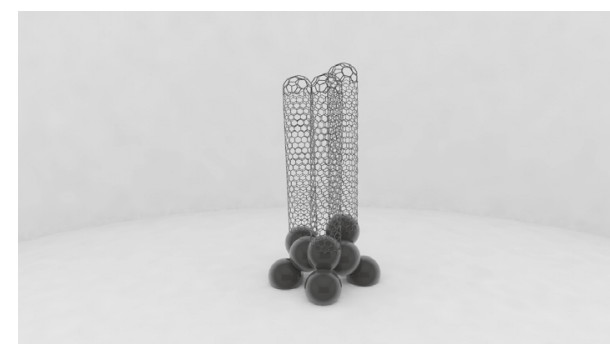

(a)

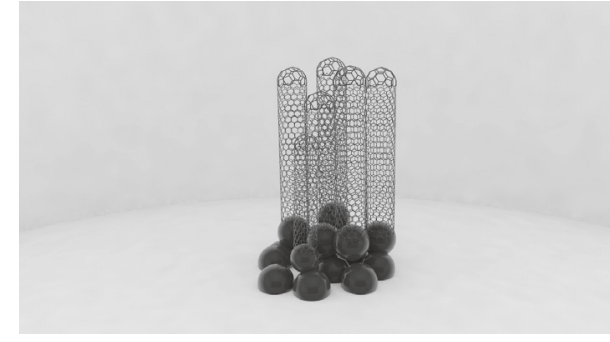

(b)

FIGURE 5: Schematics bundled SWNTs grown from cobalt clusters on $200 \mathrm{~nm}$ silica particle. SWNTs were grown from cobalt particles (black sphere). (a) Small bundle of SWNTs is grown from small size of Co cluster. This growth occurs in sample with $0.2 \mathrm{wt} \%$ solution. (b) Large bundle of SWNTs attached to large size of Co cluster. This growth corresponds to the sample with high concentration (0.4 wt\%).

$0.92 \mathrm{~nm}\left(268 \mathrm{~cm}^{-1}\right)$. The representative peaks recorded from small-bundled SWCNTs are $158 \mathrm{~cm}^{-1}$ and $207 \mathrm{~cm}^{-1}$. Diameters corresponding to these two RBM frequencies are $1.56 \mathrm{~nm}$ $\left(158 \mathrm{~cm}^{-1}\right)$ and $1.19 \mathrm{~nm}\left(207 \mathrm{~cm}^{-1}\right)$. It is clearly seen that more various diameters of SWCNTs were synthesized from large bundle sample, using $0.4 \mathrm{wt} \%$ Co-acetate ethanol solution. Also, the intensity of the RBM spectrum has relation with the population of SWCNTs at corresponding frequency. This result shows that frequencies and intensities of peaks of large-bundled SWCNTs are both higher than those of small-bundled SWCNTs. This result shows that more various SWCNT types with metallic and/or semiconducting properties and much more SWNT bundles were grown from higher concentration solution $(0.4 \mathrm{wt} \%)$. Kataura et al. [15] showed correlation between SWNTs resonance Raman scattering and band gap in a plot based on the optical transition in density of states of tubes. We studied electronic properties of our samples according to Kataura plot. Electronic properties of nanotubes are displayed in Figure 4(a). Each RBM peak was labeled M (metallic tube) or S (semiconducting tube) [16]. The samples using high concentration solution $(0.4 \mathrm{wt} \%)$ have various electronic characteristics.

We confirmed that as-synthesized CNTs have $98 \%$ purity of SWCNTs (Figures 4(b)-4(e)) using transmission electron microscope (TEM). Figures 4(b), 4(d), 4(c), and 4(e) show SWCNTs synthesized by $0.2 \mathrm{wt} \%$ and $0.4 \mathrm{wt} \%$ Coacetate solution, respectively. Both samples were grown using $200 \mathrm{~nm}$ silica particles. It can be confirmed that SWCNTs bundles were grown from Co catalysts cluster on the surface of silica nanoparticles in Figures 4(b) and 4(c). In highresolution TEM images (Figures 4(d) and 4(e)), synthesized nanotube bundle seems aligned, and bigger bundle was grown from high concentration $(0.4 \mathrm{wt} \%)$ sample. We also confirmed in Figure S1, in Supplementary Material available online at https://doi.org/10.1155/2017/6379358, that smallbundled SWNCTs have relatively high quality graphitic structures than large-bundled SWCNTs by Raman spectra analysis in the supporting information.

Different sizes of SWCNT bundles grown from Co clusters are schematically displayed in Figure 5. Figure 5(a) shows small bundle of SWCNTs made from $0.2 \mathrm{wt} \%$ Co-acetate ethanol solution. $0.4 \mathrm{wt} \%$ sample is shown in Figure 5(b). In schematics, the number of Co particles forming cluster differs according to the concentration of solution. Larger cluster is made from highly concentrated solution (0.4 wt\%). And each Co particle is catalyst for growth of SWCNTs. So, higher concentration solution can synthesize more various sizes of bundle of SWCNTs than lower concentrated solution. To conclude, the bundle size of SWCNTs is engineered by different size of cobalt cluster, that is to say, the concentration of ethanol-based Co-acetate solution.

\section{Conclusions}

In this study, we synthesized the small and large SWCNTs bundles from different-sized cobalt catalyst clusters, prepared through CVD method by using Co-acetate ethanol solution with silica nanoparticles. We have shown that more various sizes and types of bundle of SWCNTs are grown by using high concentration Co-acetate ethanol solution $(0.4 \mathrm{wt} \%)$. We synthesized SWCNTs with diameter from $0.92 \mathrm{~nm}$ to $1.63 \mathrm{~nm}$. And chirality and electronic properties of SWCNTs from high concentration solution are also various. This result is due to more and larger cobalt clusters that merged on the surface of silica nanoparticles, made from high concentration solution. And these cobalt clusters provide a lot of nucleation sites for growth of SWNTs. On the basis of our experiment, selective growth of SWCNTs can be conducted by using different shapes of merged cobalt catalyst. Further, bundle size engineering of SWCNTs can be important key for wide application of carbon nanotubes.

\section{Conflicts of Interest}

The authors declare that there are no conflicts of interest regarding the publication of this paper.

\section{Acknowledgments}

This work was supported by Inha University Research Grant (INHA-53349). 


\section{References}

[1] A. Jorio, G. Dresselhaus, and M. S. Dresselhaus, Carbon Nanotubes: Advanced Topics in the Synthesis, Structure, Properties and Applications. Topics in Applied Physics, Springer, 2008.

[2] Z. He, J.-L. Maurice, C. Lee, C. Cojocaru, and D. Pribat, The Arabian Journal for Science and Engineering, vol. 35, no. 1C, p. 19, 2010.

[3] Y. Kobayashi, H. Nakashima, D. Takagi, and Y. Homma, "CVD growth of single-walled carbon nanotubes using size-controlled nanoparticle catalyst," Thin Solid Films, vol. 464-465, pp. 286289, 2004.

[4] Z. Ren, Z. Huang, J. Xu et al., Science, vol. 282, no. 5391, p. 1105, 1998.

[5] R. Jasti and C. R. Bertozzi, "Progress and challenges for the bottom-up synthesis of carbon nanotubes with discrete chirality," Chemical Physics Letters, vol. 494, no. 1-3, pp. 1-7, 2010.

[6] C. Zoican Loebick, R. Podila, J. Reppert et al., "Selective synthesis of subnanometer diameter semiconducting single-walled carbon nanotubes," Journal of the American Chemical Society, vol. 132, no. 32, pp. 11125-11131, 2010.

[7] R. Saito, G. Dresselhaus, and M. Dresselhaus, "Physical properties of carbon nanotubes," World Scientific, 1998.

[8] R. A. Jishi, L. Venkataraman, M. S. Dresselhaus, and G. Dresselhaus, "Phonon modes in carbon nanotubules," Chemical Physics Letters, vol. 209, no. 1-2, pp. 77-82, 1993.

[9] S. Bandow, S. Asaka, Y. Saito et al., "Effect of the growth temperature on the diameter distribution and chirality of singlewall carbon nanotubes," Physical Review Letters, vol. 80, no. 17, pp. 3779-3782, 1998.

[10] J. Kürti, G. Kresse, and H. Kuzmany, Physical Review B, vol. 58, no. 14, pp. R8869-R8872, 1998.

[11] D. Sánchez-Portal, E. Artacho, J. M. Soler, A. Rubio, and P. Ordejón, Physical Review B, vol. 59, no. 19, pp. 12678-12688, 1999.

[12] A. Jorio, R. Saito, J. H. Hafner et al., "Structural (n, m) determination of isolated single-wall carbon nanotubes by resonant Raman scattering," Physical Review Letters, vol. 86, no. 6, pp. 1118-1121, 2001.

[13] S. M. Bachilo, M. S. Strano, C. Kittrell, R. H. Hauge, R. E. Smalley, and R. B. Weisman, "Structure-assigned optical spectra of single-walled carbon nanotubes," Science, vol. 298, no. 5602, pp. 2361-2366, 2002.

[14] E. Kukovitsky, S. L’vov, N. Sainov, V. Shustov, and L. Chernozatonskii, "Correlation between metal catalyst particle size and carbon nanotube growth," Chemical Physics Letters, vol. 355, no. 5-6, pp. 497-503, 2002.

[15] H. Kataura, Y. Kumazawa, Y. Maniwa et al., "Optical properties of single-wall carbon nanotubes," Synthetic Metals, vol. 103, no. 1-3, pp. 2555-2558, 1999.

[16] M. Dresselhaus and P. Eklund, "Phonons in carbon nanotubes," Advances in Physics, vol. 49, no. 6, pp. 705-814, 2000. 

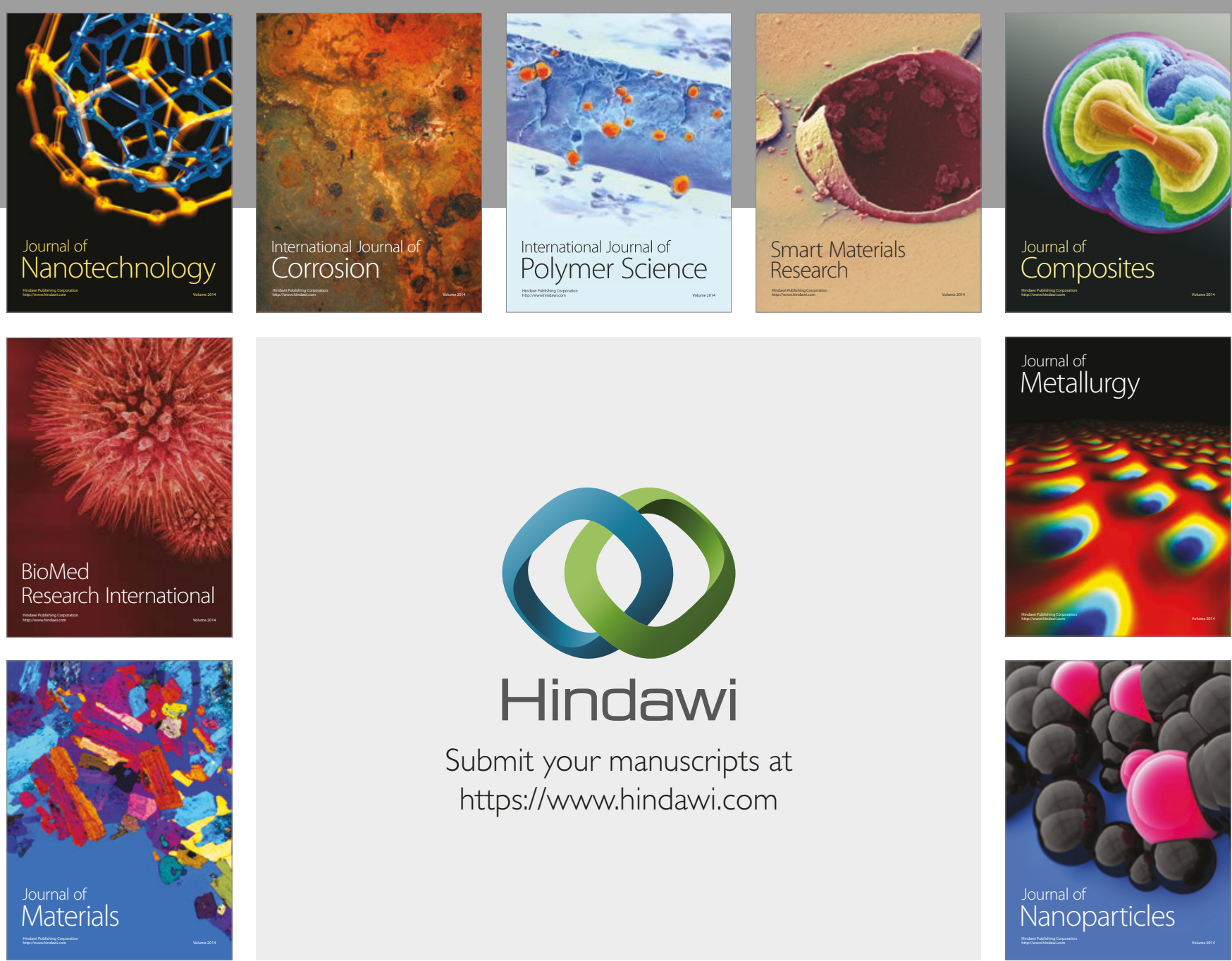

\section{Hindawi}

Submit your manuscripts at

https://www.hindawi.com
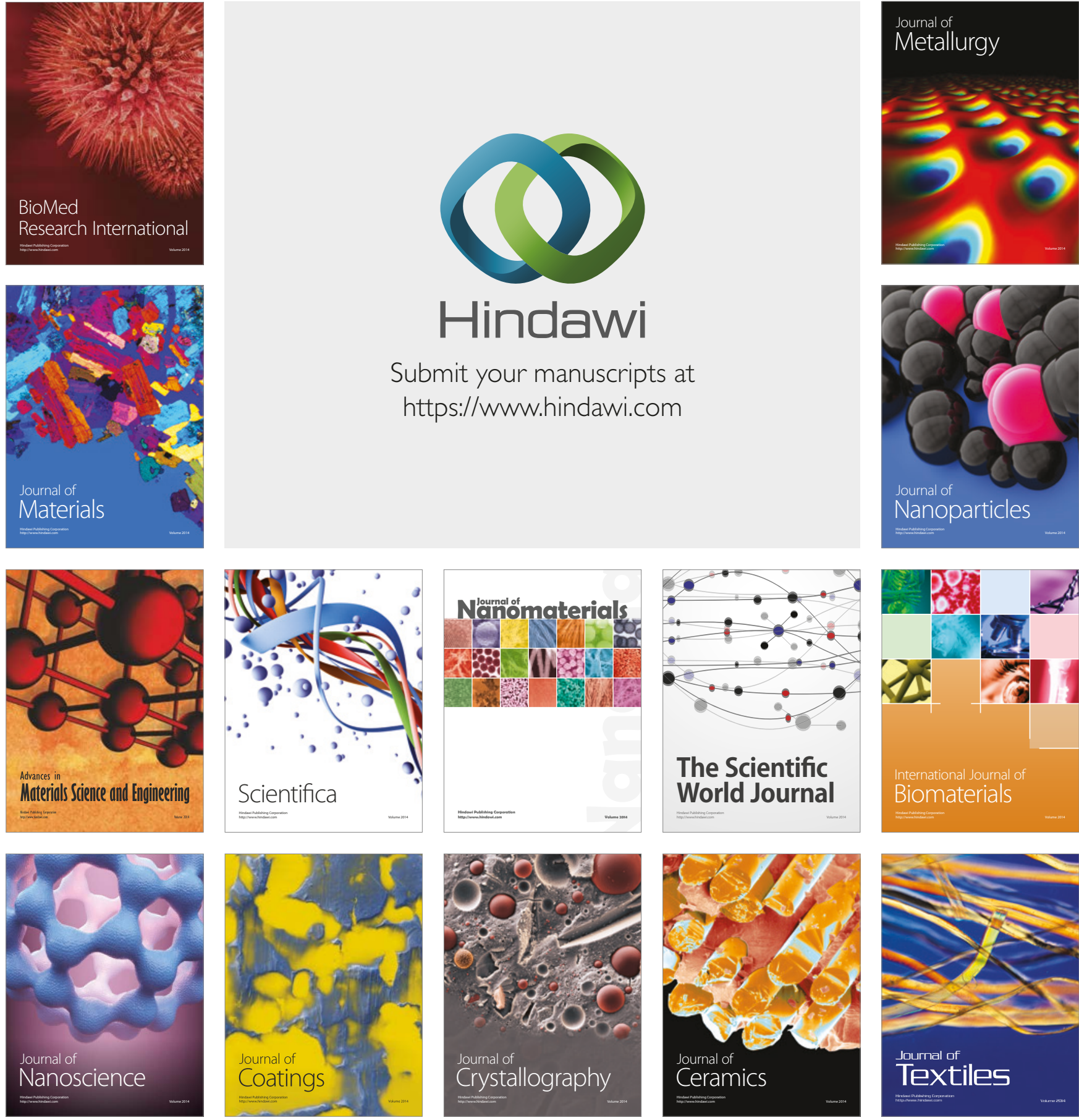

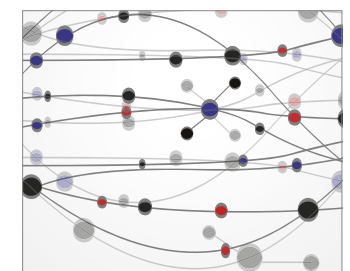

The Scientific World Journal
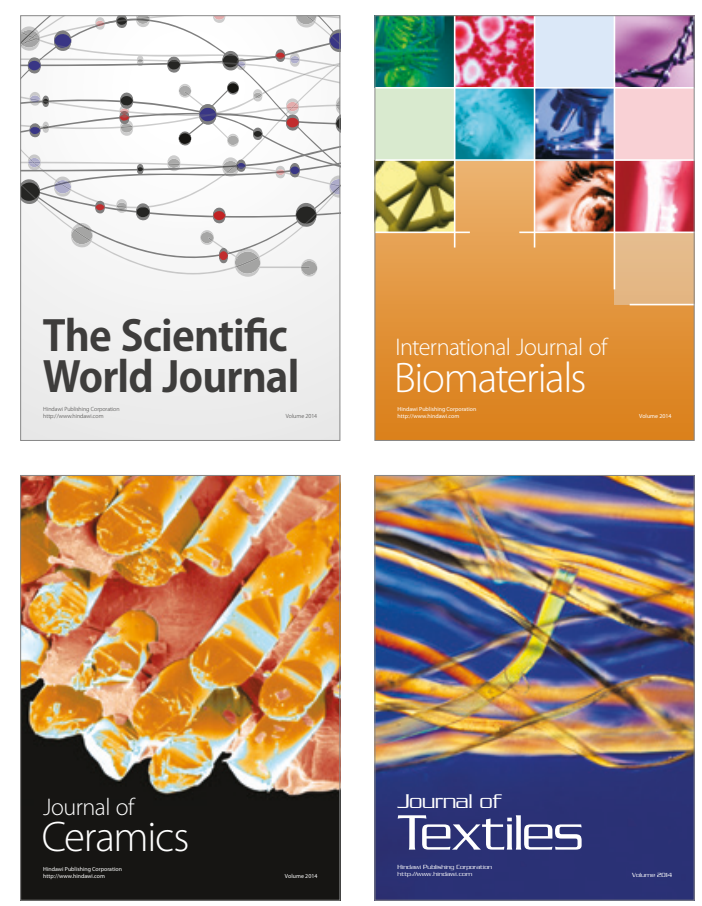